\title{
Modularization - Enabler for Shop Floor Involvement in Improvement and Development
}

\author{
Bjørnar Henriksen ${ }^{1}$, Lars Skjelstad $^{1}$, Eva Amdahl Seim ${ }^{2}$, and Carl Christian Røstad ${ }^{1}$ \\ ${ }^{1}$ SINTEF Technology and Society, 7465 Trondheim, Norway \\ ${ }^{2}$ Norwegian University of Science and Technology, 7491 Trondheim, Norway
}

\begin{abstract}
The introduction of modules and product platforms implies a strategy where the scope should encompass not a single product, but a family or an assortment of products. Instead of searching for "an optimal design for an optimal product", the objective should be to create a flexible product design, allowing product variations without requiring changes in the overall product design every time a new variant is introduced. This flexibility in product design and customization has been regarded as a feasible way for leisure boat manufacturers in high-cost countries like Norway to be competitive in the increasingly tougher conditions of the leisure boat market. The incremental development process that we often find in e.g. craft manufacturing, which leisure boat manufacturing can be seen as, is well suited for modularization. A way to introduce a module-based product architecture could be to identify key parts of the products - parts, systems or components that enable the development of modules. This paper describes how modularization makes it easier to address improvement and development in the company. This paper also reports how the focus modularization enabled profound involvements from employees that reduced barriers to change. This, over time, also challenged the traditional "craftsmen culture" into a more change-oriented and proactive culture at shop floor level.
\end{abstract}

Keywords: Modularization, improvement, leisure boat manufacturing.

\section{Introduction}

Craft manufacturing still plays an important role in the economy. Principles and skills related to craft manufacturing have shown to be important for e.g. European economies to compete with new evolving economies (see e.g. Buschfeld et al [1]). However, craft manufacturing also has to adapt to new manufacturing principles in order to be competitive. This paper aims to show how industrial principles could be implemented in an industry characterized by craft manufacturing exemplified by the leisure boat industry.

Building boats is still to a large extent craftwork based on knowledge passed on for generations. Knowledge of boats and the sea is valuable throughout the development process, from the early design stages to the physical assembly of a prototype. During design most of the boat's seaworthiness, durability and performance is determined. 
The quality of the craftwork carried out in production determines the final qualities in this regard. Craft manufacturing industries such as the Norwegian leisure boat industry has traditionally been characterized by small-scale production and high levels of customization. The companies are all small and medium sized with limited resources for R\&D and investments. Consequently, development processes have been incremental where changes have been carefully introduced over time in new or modified products and solutions.

One of the advantages of craft manufacturing is the involvement of the persons actually making the product. This personal involvement normally results in high quality and a high degree of customization. This also often goes "hand-in-hand" with improvements where the craftsman is continuously looking for improvementopportunities. However, quality and improvements need to be documented and to some extent standardized for the rest of the company and the next products to be produced.

International business competition is most challenging on cost issues for the Norwegian manufacturers. Neither the qualities nor the seaworthiness of Norwegian boats are threatened in a dramatic way. But, the industry is not prepared for the competition on costs, and quality alone is not enough to win the market.

An increased degree of modularization has been regarded as one important principle that could increase productivity and quality in general for industry (see ex Baldwin and Clark [2]; Ulrich [3]; Pine, [4]). In short, literature suggests that modularity can facilitate increasing the number of products features available while also decreasing costs [5]. The introduction of modules and product platforms implies a strategy where the scope should encompass not a single product, but a family or an assortment of products. Instead of searching for "an optimal design for an optimal product," the objective should be to create a flexible product design, allowing product variations without requiring changes in the overall product design every time a new variant is introduced. This flexibility in product design and customization has been regarded as a feasible way for the leisure boat producers in high-cost countries like Norway to be competitive in the increasingly tougher conditions of the leisure boat market.

However, even though module-based design is an efficient way of reducing product development costs, the steps for the initial module-based product design, the overall product architecture, might be found very resource-demanding for many companies. Modularization could enable more efficient development and improvement processes since this could be done by focusing on separate modules aiming to optimize them, but not necessarily focus on all the modules at the same time. The holistic module-based product architecture reduces the risk of suboptimization from separate improvement and development initiatives. More of the improvement and development processes could then be addressed to the shop floor level and the unique knowledge from the craftsmen/boat-builders could be activated and better modules/products and processes result. Hence modularization not only enables shop floor involvement in improvement and development, the involvement of employee's e.g. at the shop floor is also a prerequisite for optimized modules and design for manufacturing. 
The purpose of this paper is to illustrate how modularization could be the key for more effective production in craft manufacturing by enabling improvement and development processes from shop floor level. This study uses data gathered from group meetings, interviews and observations through a four year long R\&D-project in the leisure boat industry in Norway. The project aimed to introduce industrial principles from e.g. lean manufacturing into an industry characterized by craft manufacturing - the leisure boat industry. The methodological approach was case studies where the researchers took an active part in the change processes of two boatbuilding companies and one supplier to boat-builders.

This paper illustrates how the action research approach triggered involvement by the employees in all levels in the companies. In particular we focus on how the shop floor level could be a driving force for improvement and development within modularized product architecture, but also focus on how modularization fits the incremental product development process.

The composition of the paper is as follows: Section 2 presents relevant theoretical perspectives. Section 3 presents the four year long R\&D-project and the basic findings from the project. Section 4 focuses on the discussion, and Section 5 concludes.

\section{Theoretical Perspectives}

\subsection{Manufacturing Paradigms}

Even though new management concepts often have been abandoned before they are allowed to fully prove their relevance, we have seen that each new concept has brought new elements to the table. These elements put into a more coherent and holistic context could be regarded as paradigms [6]. Jovane, Koren and Boer [7] have developed a set of criteria to identify and describe different manufacturing paradigms. In Table 1 Henriksen and Rolstadås [8] illustrate how paradigms could be identified based on a set of similar criteria emphasizing knowledge and innovation.

Craft Manufacturing is by Jovane et al. [7] presented as a manufacturing paradigm and is based on making exactly the product that the customer asks for, usually one product at a time in a "pull-type business model"' sell (get paid) - design - make assemble. The processes have a low level of automation, but use skilled and flexible workers.

Hill [9] presents basic principles for the more recent paradigms:

- a discretionary approach to change to ensure that scarce development resources are used in those areas that will yield best returns

- as with process choice, it is necessary to establish and then choose between sets and trade-offs that go hand in hand with each decision

- the infrastructure design must respond to dynamics of reality and much of necessary change can be achieved incrementally

- continuous development is easier to bring about where the responsibility for identifying and implementing improvements is locally based 
Table 1. Manufacturing paradigms [8]

\begin{tabular}{|c|c|c|c|c|c|}
\hline \multicolumn{2}{|c|}{ Aspects } & \multicolumn{3}{|c|}{ Paradigm } & \multirow[b]{2}{*}{$\begin{array}{c}\text { Adaptive } \\
\text { manufacturing }\end{array}$} \\
\hline Field & Criteria & $\begin{array}{c}\text { Craft } \\
\text { manufacturing }\end{array}$ & $\begin{array}{c}\text { Mass } \\
\text { manufacturing }\end{array}$ & $\begin{array}{c}\text { Lean } \\
\text { manufacturing }\end{array}$ & \\
\hline \multirow{3}{*}{$\begin{array}{l}\text { Business } \\
\text { model }\end{array}$} & Started & $1850 \mathrm{~s}$ & $1910 \mathrm{~s}$ & $1980 \mathrm{~s}$ & $2000 \mathrm{~s}$ \\
\hline & $\begin{array}{l}\text { Customer } \\
\text { requirements }\end{array}$ & Customized products & Low cost products & Variety of products & $\begin{array}{c}\text { Mass customized } \\
\text { products }\end{array}$ \\
\hline & Market & $\begin{array}{c}\text { Pull. } \\
\text { Very small volume per } \\
\text { product }\end{array}$ & $\begin{array}{c}\text { Push } \\
\text { Demand }>\text { Supply } \\
\text { Steady demand }\end{array}$ & $\begin{array}{c}\text { Push-Pull } \\
\text { Supply }>\text { Demand } \\
\text { Smaller volume per } \\
\text { product }\end{array}$ & $\begin{array}{c}\text { Pull } \\
\text { Globalization, } \\
\text { segmentation } \\
\text { Fluctuating demand }\end{array}$ \\
\hline \multirow[t]{2}{*}{ Innovations } & Process - enabler & $\begin{array}{c}\text { Electricity } \\
\text { Machine tools }\end{array}$ & $\begin{array}{l}\text { Moving assembly } \\
\text { line and DML }\end{array}$ & $\begin{array}{c}\text { FMS Robots } \\
\text { Modulized products }\end{array}$ & $\begin{array}{c}R M S \\
\text { Information technology }\end{array}$ \\
\hline & Innovation process & Incremental & Linear and radical & $\begin{array}{c}\text { Incremental and } \\
\text { linear }\end{array}$ & $\begin{array}{c}\text { Incremental and } \\
\text { radical }\end{array}$ \\
\hline \multirow[t]{4}{*}{ Knowledge } & Behavior & $\begin{array}{c}\text { Practical oriented } \\
\text { (skills } \\
\text { Learning by doing) }\end{array}$ & $\begin{array}{c}\text { Centralized } \\
\text { decisionmaking. } \\
\text { Learning by } \\
\text { instructions }\end{array}$ & $\begin{array}{c}\text { Decentralized } \\
\text { decisionmaking. } \\
\text { Continuous } \\
\text { improvement } \\
\text { Learning by doing }\end{array}$ & $\begin{array}{c}\text { Decentralized } \\
\text { decisionmaking. } \\
\text { Knowledge to be } \\
\text { applied instantly }\end{array}$ \\
\hline & Knowledge creation & Tacit knowledge & Explicit knowledge & Tacit knowledge & $\begin{array}{l}\text { Tacit and explicit } \\
\text { knowledge }\end{array}$ \\
\hline & Knowledge base & Synthetic & Analytical & $\begin{array}{c}\text { Analytical and } \\
\text { Synthetic }\end{array}$ & $\begin{array}{c}\text { Analytical and } \\
\text { synthetic }\end{array}$ \\
\hline & $\begin{array}{l}\text { Knowledge transfer- } \\
\text { challenge }\end{array}$ & $\begin{array}{c}\text { Externalize knowledge } \\
\text { communicating with } \\
\text { customers }\end{array}$ & $\begin{array}{c}\text { Internalize } \\
\text { knowledge, for } \\
\text { practical use }\end{array}$ & $\begin{array}{l}\text { Externalize } \\
\text { knowledge, making it } \\
\text { more explicit }\end{array}$ & $\begin{array}{c}\text { Continuously } \\
\text { externalize and } \\
\text { internalize knowledge }\end{array}$ \\
\hline
\end{tabular}

Lean manufacturing could also be regarded as a manufacturing paradigm [8] and contains many of the above more recent principles. Lean is based on the entirely new approach to manufacturing Japanese companies developed after World War II characterized by an emphasis on reliability, speed, "just-in-time", and flexibility, rather than volume and cost [9]. Foster [10] defines "lean" as "a productive system whose focus is on optimizing processes through the philosophy of continual improvement" ([10] p. 87). One crucial insight is that most costs are assigned when a product is designed. As a consequence, product development activities should be carried out concurrently, not sequentially, by cross-functional teams [12]. Modularization is i.e. considered an enabler for flexibility and is also an important element of lean manufacturing.

\subsection{Involvement in Improvement and Development}

Innovations in companies are often a combination of incremental and radical innovations [13]. Importance and innovativeness are often as high for incremental as for radical innovations, but where incremental innovations are going through more PDCA cycle iterations [14] and hence need more time. There is also often interplay between the incremental and radical innovations since the incremental innovations often enlighten the need for more radical innovations.

In manufacturing, innovation is frequently incremental and continuous through for example, quality improvement and various lean approaches, but it can also be radical and disruptive [15]. An important dimension is whether a manufacturing strategy is based on a decentralized process, as in lean. The innovation process is much more decentralized, interactive and incremental within lean manufacturing than in for example mass manufacturing [16]. More people from different backgrounds and skill competencies are involved in the lean improvement process. However from table 1 
we also understand that craft manufacturing is even more grounded on experience and tacit knowledge based incremental innovations, than the more fact based lean manufacturing.

\subsection{Concurrent Engineering}

Concurrent engineering is the term that is applied to the engineering design philosophy of cross-functional cooperation in order to create products that are better, cheaper and more quickly brought to market. In concurrent engineering product design and production processes are developed simultaneously by cross-functional teams. The reason for this is the need to capture and integrate different aspects and the voice of the customer throughout the development process [17]. The fundamentals of concurrent engineering could be described by the following four characteristics [18]:

- $\quad$ increased role of manufacturing process design in product design decisions

- formation of cross-functional teams to accomplish the development process

- focus on the customer during the development process

- use of lead time as a source of competitive advantage

Concurrent engineering significantly modifies the sequential development (waterfall method) process and instead opts to use what has been termed an iterative or integrated development method.

A significant part of concurrent engineering is that the individual employee is given much more say in the overall design process due to the collaborative nature of concurrent engineering. Giving the designer ownership plays a large role in the productivity of the employee and quality of the product that is being produced. This stems from the fact that people given a sense of gratification and ownership over their work tend to work harder and design a more robust product, as opposed to an employee that is assigned a task with little say in the general product [19]. There is a motivation for teamwork since the overall success relies on the ability of employees to effectively work together.

\subsection{Modularization}

Modularization is currently in focus as a means for increasing competitiveness in manufacturing. This is achieved by bridging the advantages of: (1) standardization and rationalization, (2) customization and flexibility, and (3) reducing complexity [20]. Module-based design is in the same way as concurrent engineering a way of reducing product development lead time. However modularization also has many other advantages which have made it a key element in manufacturing paradigms such as lean. Modularity allows part of the product to be made in volume as standard modules while product distinctiveness is achieved through combinations or modifications of modules [5].

The cost effects through reduced product development lead time and volume effects from standardization are important, but there are also revenue aspects of 
modularization: With a modular product platform structure, a set of building blocks (modules) is created with which, through different combinations, a great number of final products can be built. Parts of the product that strategically should vary to satisfy customer needs are well defined and separated from the parts of the product that should be kept as common units. In this way, many variants of final products can be handled without increasing a company's internal complexity.

By breaking a complex product structure into smaller, manageable units, a company can regain control of the product and the product-related activities. Modularity aims at increasing efficiency by reducing complexity. The modular approach implies building an optimal product assortment that takes into consideration development, design, variety, manufacture, quality, purchase, and after-sales service, in other words, the entire product life-cycle. A cornerstone of modularity is the adoption of a common view of the product throughout the entire organization. This opens up a window of opportunities for concurrent engineering and improvement, decentralization and shop floor involvement.

We often find module-based design within incremental product development, where e.g. not all innovations or "novelties" are introduced at the same time. However, the initial module-based product architecture are often described as a systematic approaches with steps such as in Modular Function Deployment (MFD) [20]: (1) design requirements, (2) identification of functions that fulfill the demands and their corresponding technical solutions, (3) technical solutions are analyzed regarding their reasons for being modules, (4) module concepts are then generated and the interface relations of the modules derived are evaluated. In the final step, (5) a specification is established for each module. A systematic approach needs knowledge from people that knows customer demands, service requirements, and from those producing the products. Concurrent engineering could be a key to mobilize and capture this knowledge in development processes.

The tendency towards a more abstract understanding of modularity is further strengthened by the fact that modularization in an industrial context can be seen as reuse of engineering and employee resources for companies that are increasingly aware of knowledge as a competitive advantage [21]. An important part of the knowledge of the company is embedded in the products and reusing modules knowledge saves time and money. It is not necessarily the finished, physical modules that are reused in order to gain the benefits. Also, so-called intellectual reuse of earlier stages, like reuse of engineering specifications, testing, process engineering etc, may lead to the desired effects by blurring the boundary between knowledge management and traditional modularization [22].

\section{The ISB-Project}

\subsection{The Project}

The ISB-project (Industrialized Small scale Production of Leisure Boats) was a 4-year R\&D-project that started in 2008 at the same time as the global financial crisis hit the leisure boat market. However, the background for the project was not to meet the 
difficult market situation, but rather the structural challenges from low-cost producers and the larger, more "industrialized" actors in the industry.

The overall objective of the project was to initiate a transformation of the craftoriented leisure boat production into a more competitive way of production by introducing more state-of-the-art principles from manufacturing. The overall challenge of the project has been to keep or improve the high quality level and customization that is the characteristic of craft manufacturing, and at the same time create more cost-efficiency. This implies becoming more lean and aiming for mass customization. The focus of the project was on modularization and standardization of work processes.

\subsection{The Partners}

The project had three industrial partners, two Norwegian boat-builders and one supplier to boat-builders. There was also two Norwegian R\&D partners (SINTEF and the Norwegian University of Science and Technology). The project was co-financed by The Norwegian Research Council.

The boat-builders had different focus and the project was organized in four workpackages with the industrial partners owning three of them, (1) module-based design, (2) standardized work processes and knowledge management, and (3) supply chain integration. The fourth work package was dissemination.

The largest boat-builder (OEM) with models from 25 to 58 feet had a turnover of 16 million $€$ (2011), employed about 80 people (2011), with manufacturing units in two countries in addition to the mother plant, and customers and suppliers from all continents. The other company made 18 to 27 feet boats and had a turnover of about 4 million $€(2011)$.

Even though these two companies have defined product-lines, the level of customization is high. This makes the manufacturing processes difficult to e.g. automate. For instance, the customer's choice of a larger freshwater-tank impacts the boats stability, thus requiring a reconfiguration of installment of other components and adjustments to e.g. brackets and bars. Manufacturing processes are mainly manual and adjustments are made all along the boat manufacturing process. The quality of the boats is perceived by the market as very high, but also with prices in the high end. Boatbuilding also has other typical characteristics of craft manufacturing such as manual experience-based and incremental product development. Tacit knowledge is the basis for improvement and development and a typical statement could be "what happens at the shop floor stays at the shop floor".

The supplier is a key actor in the boatbuilding industry as it is the biggest and most important supplier of their products in the Scandinavian boatbuilding industry. The company has a turnover of about 7 million $€$ (2011) and is within the mechanical engineering industry, but still has many of the same characteristics of craft manufacturing. The case presented in this paper is in particular based on the largest boat-builder, the supplier and the relation between these two companies. 


\section{Involving Shop Floor Level in Improvement and Development}

\subsection{From Skepticism to Driving Force}

At an early stage of the ISB-project, the researchers set out to get an overview of the existing design and production processes. The overview of the production was done by setting up work groups basically from the shop floor (production group). Initially these work groups reflected skepticism among the workers for change. They wanted to keep the identity of being a craftsman and they were not very motivated for standardization of work processes. But this changed during the work session where their work processes and challenges where analyzed and documented, and they could see how their work situation could be improved as a result of measures aiming to improve productivity. Waste reduction and other lean methods are example of such methods.

As the production group, under facilitation by researchers, digged deeper into improvement they turned more of their attention from improvement of todays processes and into product design. They identified how their work could be improved and also the products by redesign products or parts. The discussions where also particularly fruitful when the workers/craftsman discussed the particular area of the boat they normally worked on (e.g. engine room). They showed not only good skills in their work/operations, but also an extremely high knowledge, identity and loyalty to the product and boat area as the discussions become concrete to them. During the project the production work groups made several suggestions for modularization, but also involved themselves in the suggestions for other modules such as cockpit, softhatch to handle opening/closing a soft-top and cabling/wiring.

An important finding in the project was the need for a structure for capturing the knowledge and initiatives from the shop floor level. This included a more teamoriented organization at shop floor level, and methods like stand-up meetings (10 minutes) as a daily starting point in the mornings as an arena for daily planning and work related issues. The team leader got responsibility for following up issues and suggestions from these meetings e.g. by own decisions or bringing them up to higher level meetings and decision bodies.

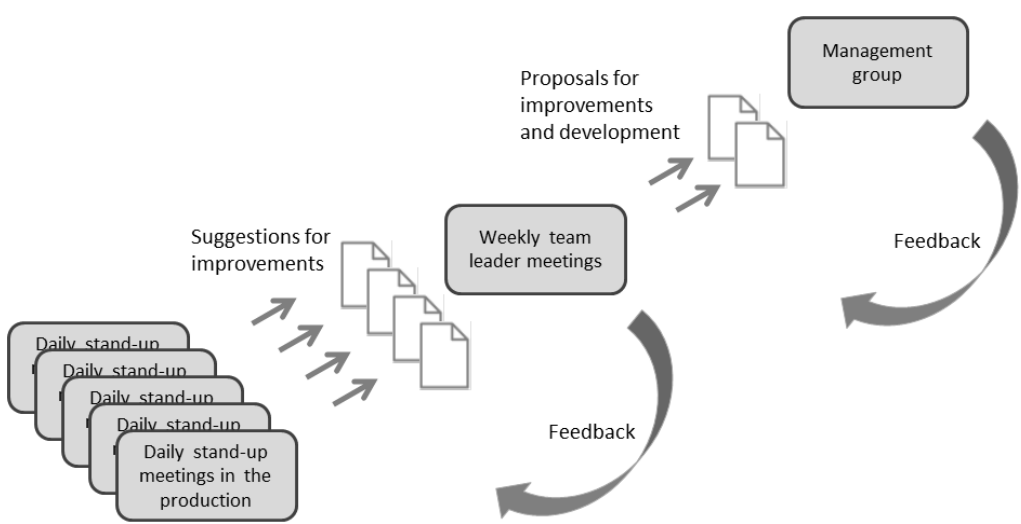

Fig. 1. Structure for improvement and involvement from shop floor level 
Another important part of the structure for improvement was that discussions and decisions should be more fact-oriented. Thus, tacit knowledge had to be codified through different types of forms, but this also required training of the workers of how to be more explicit. An improvement tool called SMART was developed trough the ISB-project. The methodology resembles the A3 tool in lean, but adjusted to the context of leisure boat manufacturing.

\subsection{Concurrent Engineering - Internally and with the Supplier}

Standardization of work processes is a prerequisite for modularization as this also improves lead times using standardized modules and parts. Further, standardized work processes must be as efficient as possible. Thus, the production/shop floor level needs to be involved concurrently in the design process of products and modules. This was not the case in the companies when the ISB-project started. In fact, boat design had been seen as an "art" where the visual design was the basis and where the design group to a large extent then accomplished the design from the artist with technical and practical solutions and specifications. Even though there were some discussions between the design group and the production, there were no structured concurrent involvements. The same was the case for the involvement of the supplier in the design - they were often just asked to develop and deliver whatever the designer decided, no matter the price (which first became an issue after the supplier had come up with solutions which prolonged the development process).

During the project period several new boat models were launched and the need for å more concurrent development process became clearer. Two years into the project the new 40 feet model was developed as a much more structured project with a proper development team including market and production, and with weekly meetings together with the workers building the prototypes. Also the supplier was more involved in the design process as they got responsibility for developing the "softhatch" module. However, the relation between the boat-builder and the supplier was not very structured, and were more based on personal relations and tacit knowledge. This was addressed as a major improvement aspect in the evaluation meeting at the end of the development process of the soft-hatch involving people from the boatbuilder (design, production, marketing and sales) and the supplier (including external engineering consultants).

To assure a more concurrent and efficient product development a new leanoriented project-model was developed based on the following principles:

- understand customer requirements and early focus on gaps

- design to target cost

- make decisions based on facts

- capture and maintain knowledge

- visualize

- "right from me"

- modularization

- early sub-system testing 
The project model has several meeting points and learning loops to assure learning and involvement through the project phases: (1) Concept - design brief, (2) Design solutions and specifications, (3) Prototype - physical design, (4) Validation - testing, evaluation, choice, (5) Production process - suppliers, tools, procedures, and (5) Evaluation - product and processes.

\subsection{Incremental Modularization Top-down versus Bottom-up}

The idea of modularization was not met with enthusiasm, mainly due to the challenge towards business traditions of craftwork explained in 4.1. But a general interest for improving business initiated several initiatives to achieve modularity both in the boatbuilding companies and the supplier. The main motivation was to increase volumes on some parts. In the biggest boat-building company a work group was set up to focus on modularization.

Even though the ISB-project was aiming for a holistic approach to modularity, a completely modularized new boat is resource demanding and was not the ambitions for the ISB-project. However, the 5 steps of MFD was a reference for our work. This means that the project started with a kind of top-down approach where the work group was going through the basic elements of the new boat model to identify the best possible starting point - the first module to be developed. During work sessions several possible modules where discussed and analyzed but where typically rejected or postponed by the designers under arguments such as, "they could have negative impact on company identity", "on quality" etc. However, the work group agreed on a module or platform that was not visible for the customer, namely the important electric wiring of a boat. Here, new interfaces and new functions based on bustechnology are opening for more standardized marine solutions. The traditional wiring in a medium size boat weights some $250 \mathrm{~kg}$ and requires a lot of work and leaves little flexibility for alterations after being installed. Any modification to decrease complexity, volume and weight of this part will reduce installation work and cost.

An example of a more typical top-down module is the introduction of a grid or a stringer inside the bottom of the hull. This is a structure of beams put into the boats inside to give strength to the construction and to provide interfaces towards other major parts, such as pantry, toilets, engines and cockpit. It will in the future be the main module in a boat, opening for a lot of other modules. To introduce this, a lot of engineering has to be done as a total new construction has to be made. First solutions have been introduced, but to fully exploit the potential, several interfaces still have to be worked on. This top-down modularization will in the end represent the biggest potential, and might even change the way boats are built.

The quickest, smallest and most isolated cases are denoted bottom-up initiatives. These are easy to implement because of their minor impact on neighboring parts and designs. They also involve employees in a way that seems to encourage participation. One example is the new so called "soft-hatch", which is a new way of opening the roof of soft-tops. The hatch can be scaled to fit small and large boats, and can be built in series to increase efficiency. The initiative for developing this module was not from 
a structured top-down process from the design work group. It was rather a result of concrete discussions about a design challenge for the new 40 feet. This discussion involved also the supplier in the ISB-project and resulted in an agreement of outsourcing the design of the new soft-hatch to them.

The process of developing this module is quite typical for how discussions about improvement and development become more fruitful when they are related to a concrete product (or part of a product) and production process. As we have seen from the ISB-project this might end up in modularization. What is important is that these modules are not sub-optimized in a way that reduces the overall performance of the product and processes. They must meet the overall criteria for a holistic product architecture.

\section{Conclusion}

The incremental development process that we often find in e.g. craft manufacturing is well suited for modularization. This means that a company could develop e.g. product modules step by step, and plan how these modules could be replaced or improved incrementally. The ISB-project identified the "wiring" and "inner liner" as examples of modules and platforms from a top-down approach and "hatch-top" as an example of modules developed from concrete discussions at shop floor level and with designers - bottom-up.

The ISB-project has shown how modularization makes it easier to address improvement and development in the company. This is in line with the broader perspectives on modularization where modules also are seen as "knowledge containers". Focus on modules also enabled profound involvements from employees that reduced barriers to change, that over time also challenged the traditional "craftsmen culture" into a more change-oriented and proactive culture at shop floor level. As a result of this cultural change, modules were identified, piloted and implemented in the course of the project.

\section{References}

1. Buschfeld, D., Dilger, B., Heß, L.S., Scmid, K., Woss, E.: Identification of future skills needs in micro and craft(-type) enterprises up to 2020 - Final report. Service Contract No. 30-CE-0319368 European Commission, DG Enterprise and Industry, Unit F.2 - Small Businesses, Cooperatives, Mutuals and CSR; Financed by the European Union, Forschungsinstitut für berufsbildun gim handwerk an der Universität Köln (2011)

2. Baldwin, C., Clark, K.: Modularity in design: An analysis based on the theory of real options. Working paper. Harvard Business School, Boston (1994)

3. Ulrich, K.: The role of product architecture in the manufacturing firm. Working Paper. MIT, Sloan School of Management (1992)

4. Pine, B.J.: Mass Customization. Harvard Business School Press, Boston (1993)

5. Duray, R.: Mass Customizers use of inventory, planning techniques and channel management. Production Planning \& Control 15(4), 412-421 (2004) 
6. Henriksen, B.: The Knowledge dimension of manufacturing strategy. Doctoral thesis, Norwegian University of Science and Technology (2010)

7. Jovane, F., Koren, Y., Boer, C.R.: A present and future of flexible automation: towards new paradigms. Annals of the CIRP 53(1), 543-560 (2003)

8. Henriksen, B., Rolstadås, A.: Knowledge and manufacturing strategy - How different manufacturing paradigms have different requirements to knowledge. Examples from the automotive industry. International Journal of Production Research 48(8), 2413-2430 (2010)

9. Hill, T.: Operations management: strategic context and managerial analysis. Macmillan, London (2000)

10. Foster, T.S.: Managing quality - Integrating supply chain. Prentice Hall, New Jersey (2006)

11. Womack, J.P., Jones, D.T., Roos, D.: The machine that changed the world: The story of lean Production. Harper Business, New York (1990)

12. Rolstadås, A., Henriksen, B., O’Sullivan, D.: Manufacturing outsourcing - a knowledge perspective. Springer Publishing, London (2012)

13. Deming, W.E.: Out of Crisis Boston. MIT/CAES, Cambridge, MA (1986)

14. Tidd, J., Bessant, J., Pavitt, K.: Managing innovation: Integrating technological, market and organizational change. Wiley, London (2005)

15. Cooper, R.G.: Product leadership: creating and launching superior new products. Perseus, New York (2000)

16. Smith, R.P.: The Historical Roots of Concurrent Engineering Fundamentals. IEEE Transactions on Engineering Management 44(1) (1997)

17. Jo, H.H., Parsaei, H.R., Sullivan, W.G.: Principles of concurrent engineering. In: Concurrent Engineering: Contemporary Issues and Modern Design Tools, pp. 3-23. Chapman and Hall, New York (1993)

18. Rosenblatt, A., Watson, G.: Concurrent Engineering. IEEE Spectrum, 22-37 (July 1991)

19. Ericsson, A., Erixon, G.: Controlling Design Variants: Modular Product Platforms. ASME Press, NY (1999)

20. Miller, T.D., Elgård, P.: Design for Integration in Manufacturing. In: Proceedings of the 13th IPS Research Seminar, Fuglsoe. Aalborg University (1998) ISBN 87-89867-60-2

21. Sanchez, R., Mahoney, J.T.: Modularity, Flexibility, and Knowledge Management in Product and Organization Design. IEEE Engineering Management Review 17 (1996) Reprint from Strategic Management, Special Issue December 